\title{
Investigation of a root zone heating system for greenhouse seedling and its effects on micro-environment
}

\author{
Fen $\mathrm{He}^{1,2}$, Yong $\mathrm{Hou}^{1,2}$, Kai $\mathrm{Li}^{1,2}$, Xiaoming $\mathrm{Wei}^{1,2,3^{*}}$, Yaqing $\mathrm{Liu}^{1,2}$ \\ (1. Academy of Agricultural Planning and Engineering, Ministry of Agriculture and Rural Affairs, Beijing 100125, China; \\ 2. Key Laboratory of Farm Building in Structure and Construction, Ministry of Agriculture and Rural Affairs, Beijing 100125, China; \\ 3. Beijing Research Center of Intelligent Equipment for Agriculture, Beijing 100097, China)
}

\begin{abstract}
Under the extremely cold climatic condition, crops have to survive severe heat stress conditions, even if they are being kept in greenhouses. In the winter and spring of North China, the air and soil temperature is low inside the greenhouse, and when using a traditional heating system, the energy consumption is high. This paper reports on a study of different design solutions for a root zone heating system based on a kind of low temperature radiation material. Root zone heating systems offer increasing crop quality and productivity. A novel type of heat preservation and root zone heating system was applied in greenhouse seedling. And through multiple experiments, the effect of the root zone heating system on the ambient environment and seedbed surface was studied, and the heat preservation effect and heating uniformity were discussed. Results show that single-layer film covering on the root zone heating system can make the average temperature at night increase $1^{\circ} \mathrm{C}$. And the average seedbed surface and substrate temperature can increase $11.3^{\circ} \mathrm{C}$ and $5.2^{\circ} \mathrm{C}$, respectively. In conclusion, the root zone heating system can effectively improve the environmental temperature of seedling and the uniformity of heating is high, which provides a strong guarantee for high-quality seedling cultivation.
\end{abstract}

Keywords: greenhouse, root zone heating system, micro-environment, seedling, substrate temperature, air temperature DOI: $10.25165 /$ j.ijabe.20201306.5905

Citation: He F, Hou Y, Li K, Wei X M, Liu Y Q. Investigation of a root zone heating system for greenhouse seedling and its effects on the micro-environment. Int J Agric \& Biol Eng, 2020; 13(6): 47-52.

\section{Introduction}

As an important link to vegetable production, the seedling is one of the key technical measures to improve the comprehensive benefit of vegetable production. Seedling quality has a significant impact on the vegetable planting effect. In the winter and spring of North China, the main facilities used for seedling cultivation are mainly multi-span greenhouse and solar greenhouse. The multi-span greenhouse can realize the control of temperature, humidity, light and other environments, but it has large initial investments, large energy consumption in winter and high operation cost. The solar greenhouse has good heat preservation performance, low energy consumption and low construction cost, but it has little environmental control. When there is no external heating, seedlings are faced with low temperatures and cold damage. In order to protect crops from freezing, most greenhouse production uses fossil energy consumption to heat up with water and air as the heat medium. The heating equipment mainly includes boiler and heat dissipation end, air source and ground source heat pump $\mathrm{p}^{[1,2]}$, underground heat storage system ${ }^{[3-6]}$, infrared heating system ${ }^{[7]}$, etc. These types of equipment have more initial investments, large floor area, and low automation degree.

Received date:2020-05-18 Accepted date: 2020-11-05

Biographies: Fen He, $\mathrm{PhD}$, research interest: greenhouse environment engineering, Email: hefen_2005@163.com; Yong Hou, Bachelor, research interest: agricultural engineering, Email: houyong@aape.org.cn; Kai Li, PhD, research interest: agricultural engineering, Email:likai@aape.org.cn; Yaqing Liu, MS, research interest: agricultural engineering, Email: liuyaqing@aape.org.cn. *Corresponding author: Xiaoming Wei, $\mathrm{PhD}$, Professor, research interest: agricultural engineering. Academy of Agricultural Planning and Engineering, Ministry of Agriculture and Rural Affairs, Beijing 100125, China. Tel: +86-13811328835, Email: weixiaoming836@163.com.
Moreover, most of the heating types of equipment mainly heat air, because of the large heat dissipation of the greenhouse envelope structure, the heating efficiency is low. For example, the heat dissipation of the front roof of the solar greenhouse accounts for $50 \%-60 \%$ of the total heat dissipation.

Root zone heating can directly heat the crop root area. It can provide proper temperatures to the root of crops, and stimulates plant development and flower production, and makes an increase in productivity ${ }^{[8,9]}$. Root zone heating can be combined with air heating; nevertheless, heating specifically the root zone can reduce fuel consumption rather than heating the air of the greenhouse. Attar ${ }^{[10]}$ proposed a solar system for heating a greenhouse equipped with a buried exchanger, and it can increase the inside air temperature of the greenhouse by $5^{\circ} \mathrm{C}$. Zhang et al. ${ }^{[11]}$ used the heating line to carry out winter cucumber seedling raising and cultivation experiments. Zhao et al. ${ }^{[12]}$ and Li et al. ${ }^{[13]}$ studied the application effect of carbon crystal electric plate in winter cucumber seedling in the solar greenhouse. The results showed that the heating of carbon crystal electric plate with $80 \mathrm{~W} / \mathrm{m}^{2}$ laying power could raise and maintain the night temperature of the substrate at $18^{\circ} \mathrm{C}$, the time of cucumber seedling emergence was short, the growth was fast and robust. Ding et al. ${ }^{[14]}$ and He et al. ${ }^{[15]}$ designed a hot water heating system based on a capillary pipe network, which can effectively improve the local temperature of the seedbed and had good heating uniformity. Beyza et al. ${ }^{[16]}$ and Llorach-Massana, et al. ${ }^{[17]}$ all used phase change materials (PCM) for root zone heating, but the temperature was difficult to control. Muhammad et al. ${ }^{[18,19]}$ designed a nested double-layer cultivation pot in which silicone rubber heating plates were placed for root heating to solve the low temperature of the Yangtze River delta region of China. All of these methods use electricity as energy to generate heat directly, which can solve the problem of small-scale 
seedling in the winter of the greenhouse.

Carbon crystal electric heating film is a kind of semitransparent polyester film that can generate heat after being electrified. It has excellent properties such as high pressure resistance, moisture resistance, and is mostly used for low-temperature radiation heating in civil buildings ${ }^{[20,21]}$. He, et al. ${ }^{[22]}$ compared the heating effects of heating cable, self-limiting heating zone and carbon crystal electric heating film on the seedling root area, and found that the heating effect and uniformity of carbon crystal electric heating film were the best.

The objective of the work was to combine the carbon crystal electrothermal film with the seedling production, design and develop a set of seedling heat preservation and root zone heating system, through the test of the heating effect of the system during the winter period, to provide a large-scale commercial seedling raising equipment with the controllable environment in the future.

\section{Materials and methods}

\subsection{Root zone heating system description}

In this study, the structure of the seedling heat preservation and root zone heating system is shown in Figure 1. The system is mainly composed of the upper tip arch heat preservation cover, heating materials and overall control system. The heat preservation function of the system is mainly covered by a single layer of film. In order to prevent the heat of active heating from transferring vertically to the lower part of the seedbed, the upper part of the seedbed is successively provided with a heat preservation and insulation layer, a heat reflection film and a low-temperature radiation layer. Polystyrene board with small thermal conductivity can be selected as a thermal insulation layer, the non-woven reflective film can be selected as thermal reflection film, and carbon crystal electrothermal heating film can be used as heating material for low-temperature radiation layer. The thermal energy produced by the carbon crystal electrothermal film is transmitted in the form of far-infrared radiation (peak wave is $8 \mu \mathrm{m}$ to15 $\mu \mathrm{m}$ ) and convection. The conversion rate of electric energy and thermal energy is over $98 \%$.
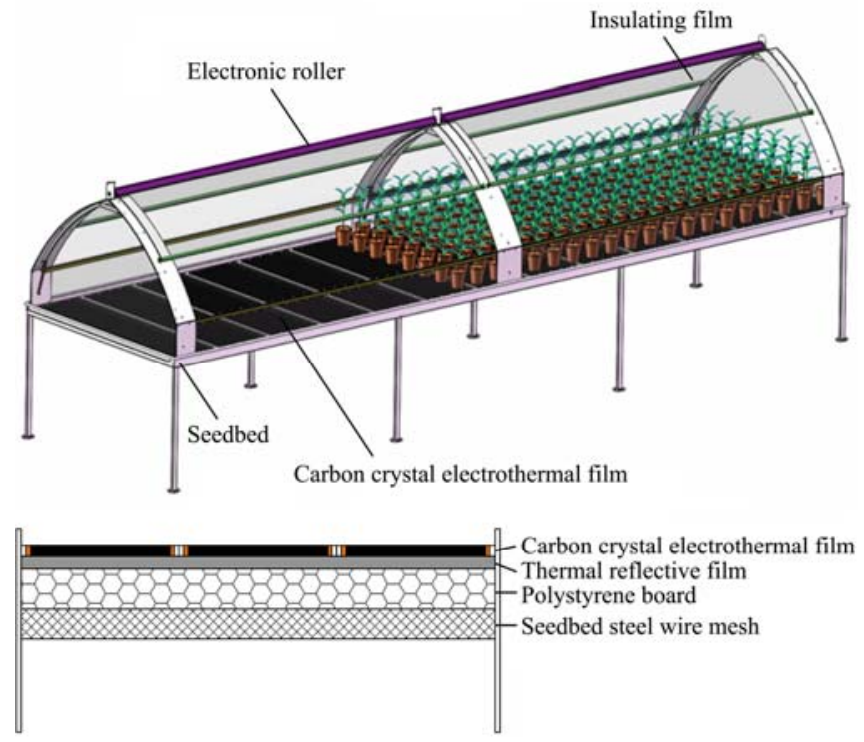

Figure 1 Overall structure and section of seedling heat preservation and root zone heating system

The control system of the heating system mainly included two parts, which were the heating control of carbon crystal electric heating film and the rolling control of external thermal insulation covering film. In the heating control part, the set temperature, temperature hysteresis, temperature rising speed and maximum temperature were used as the control thresholds. If the heating mode was turned on, when the real-time temperature was greater than the sum of the set temperature and temperature hysteresis, turned off the heating; when the real-time temperature was less than the set temperature and the temperature hysteresis difference, turned on the heating. When the measured temperature rise rate was lower than the set temperature rise rate, the system will remind that the temperature rise rate was too slow and the automatic heating will be turned off; when the temperature of the electric heating film exceeds the maximum temperature, it will remind that the temperature of the seedbed is too high and the automatic heating will be turned off. The rolling up time and the dropping time were set in a fixed time to control the running of the external thermal insulation covering film.

\subsection{Heat loss analysis and heating load calculation model}

The calculation of heat load is the most basic data analysis in heating system design, which directly affects the selection of heating schemes and equipment, the use of the heating system and economic effect. Through analysis of heat loss which was shown in Figure 2, the heating load model was constructed as follows:

$$
Q_{h}=Q_{\text {rad }}+Q_{\text {cac }}+Q_{\text {soil }}+Q_{\text {vent }}+Q_{\text {tran }}
$$

where, $Q_{h}$ is the heating load of seedling preservation and heating system, W; $Q_{\text {rad }}$ is the heat transfer through radiation, W; $Q_{c a c}$ is the heat transfer with outside air, W; $Q_{\text {soil }}$ is the heat transfer through soil or substrate, $\mathrm{W}$, as there is polystyrene board as an insulation layer, then this part can be calculated as zero; $Q_{\text {vent }}$ is the heat loss by infiltration, W; $Q_{\text {tran }}$ is the heat loss by crop transpiration, W, because the system was used for seedling, the leaf area is small, which makes the transpiration can be ignored.

$Q_{\text {rad }}$ can be calculated by Equation (2).

$$
Q_{\text {rad }}=\varepsilon \times A_{c} \times \sigma \times\left(T_{i}^{4}-T_{o}^{4}\right)
$$

where, $\varepsilon$ is the joint emissivity between the surface of the heating system and the outside air; $A_{c}$ is the area of heating system surface, $\mathrm{m}^{2} ; \sigma$ is the Stefan-Boltzmann constant, $5.67 \times 10^{-8} \mathrm{~W} /\left(\mathrm{m}^{2} \cdot \mathrm{K}^{4}\right) ; T_{i}$, $T_{o}$ is the inside and outside temperature of heating system, $\mathrm{K}$.

$Q_{\text {cac }}$ can be calculated by Equation (3).

$$
Q_{c a c}=K_{c} \times A_{c} \times\left(T_{i}-T_{o}\right)
$$

where, $K_{c}$ is the heat transfer coefficient of covering material, $6.8 \mathrm{~W} /\left(\mathrm{m}^{2} \cdot \mathrm{K}\right)$.

$Q_{\text {vent }}$ can be calculated by Equation (4).

$$
Q_{\text {vent }}=L_{v} \times C_{p} \times \rho_{a} \times\left(T_{i}-T_{o}\right) / 3.6
$$

where, $L_{v}$ is the ventilation volume of a gap, $\mathrm{m}^{3} / \mathrm{s} ; \rho_{a}$ is the air density, $1.29 \mathrm{~kg} / \mathrm{m}^{3} ; C_{p}$ is air constant specific heat capacity, $1030 \mathrm{~J} /(\mathrm{kg} \cdot \mathrm{K})$.

According to Equations (1)-(4), the heating load can be calculated. Then the power of the heating system can be determined.

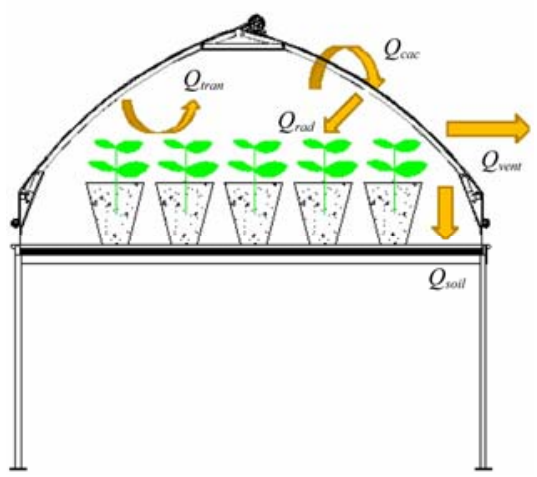

Figure 2 Heat loss analysis of heating system 


\subsection{Experimental measurements description}

In this experimental study, measurements were carried out in a Venlo greenhouse which located in Yongqing County, Hebei Province from December 19, 2019, to January 3, 2020, and the latitude is $116^{\circ} 30^{\prime} \mathrm{N}$, longitude is $39^{\circ} 12^{\prime} \mathrm{E}$. The orientation of greenhouses is North-South, and it occupies a surface area equal to $576 \mathrm{~m}^{2}$. The wide and long are respectively $16 \mathrm{~m}$ and $36 \mathrm{~m}$. The heights of the sidewall and ridge are $6.0 \mathrm{~m}$ and $6.8 \mathrm{~m}$, respectively. It is equipped with a hot water heating system, an external shading system, a wet curtain fan cooling system, etc.

Three sets of seedling bed systems were installed in the experimental area which was set as a normal seedling area, seedling heating area with heating and without heating, respectively. Each area is $11.05 \mathrm{~m}^{2}$ with $6.50 \mathrm{~m}$ long and $1.70 \mathrm{~m}$ wide. The carbon crystal electric heating film used in the test is in the shape of the surface, $0.25 \mathrm{~mm}$ thick and $50 \mathrm{~cm}$ wide. The length was cut according to the heating area of $25 \mathrm{~cm}$. The surface temperature of carbon crystal electrothermal film can reach $50^{\circ} \mathrm{C}$, single side heat dissipation, heating density $120 \mathrm{~W} / \mathrm{m}^{2}$.

The substrate temperature is used as the control threshold. The temperature and temperature hysteresis are set as $24^{\circ} \mathrm{C}$ and $1^{\circ} \mathrm{C}$, respectively. When the real-time temperature is more than $25^{\circ} \mathrm{C}$, the system turns off. When the real-time temperature is less than $23^{\circ} \mathrm{C}$, the system turns on. The setting rolling time of the external insulation covering film is on 9:30 and 16:00 every day.

Several climatic parameters were measured. The air temperature and humidity inside and outside the multi-span greenhouse and in the seedling area were measured by the temperature and humidity recorder with model TR-72U purchased from Beijing Channel Science Equipment Co., Ltd, which has a measuring range of $-20^{\circ} \mathrm{C}$ to $80^{\circ} \mathrm{C}$ and $10 \%$ to $95 \%$, respectively, and the accuracy is $\pm 0.3^{\circ} \mathrm{C}$ and $\pm 5 \%$. The substrate temperature and the seedbed surface temperature were measured by the intelligent soil thermometer recorder with model TJ1 produced by Beijing Hezhong Bopu Technology Development Co., Ltd, which has a measuring range of $-20^{\circ} \mathrm{C}$ to $80^{\circ} \mathrm{C}$, and the accuracy was $\pm 0.2^{\circ} \mathrm{C}$. The data sampling interval was set $10 \mathrm{~min}$. The height of the air temperature and humidity recorder in the greenhouse was $1.5 \mathrm{~m}$ from the ground. Nine substrate temperature sensors that were divided into three rows and three columns were embedded in the cavity tray. The surface temperature of the seedbed sensor was fixed on the seedbed, and the upper part was covered by the heat reflection device. The outside air temperature and humidity recorder were placed in the open field area, with a height of $3 \mathrm{~m}$ from the ground. The measuring point distribution is shown in Figure 3.

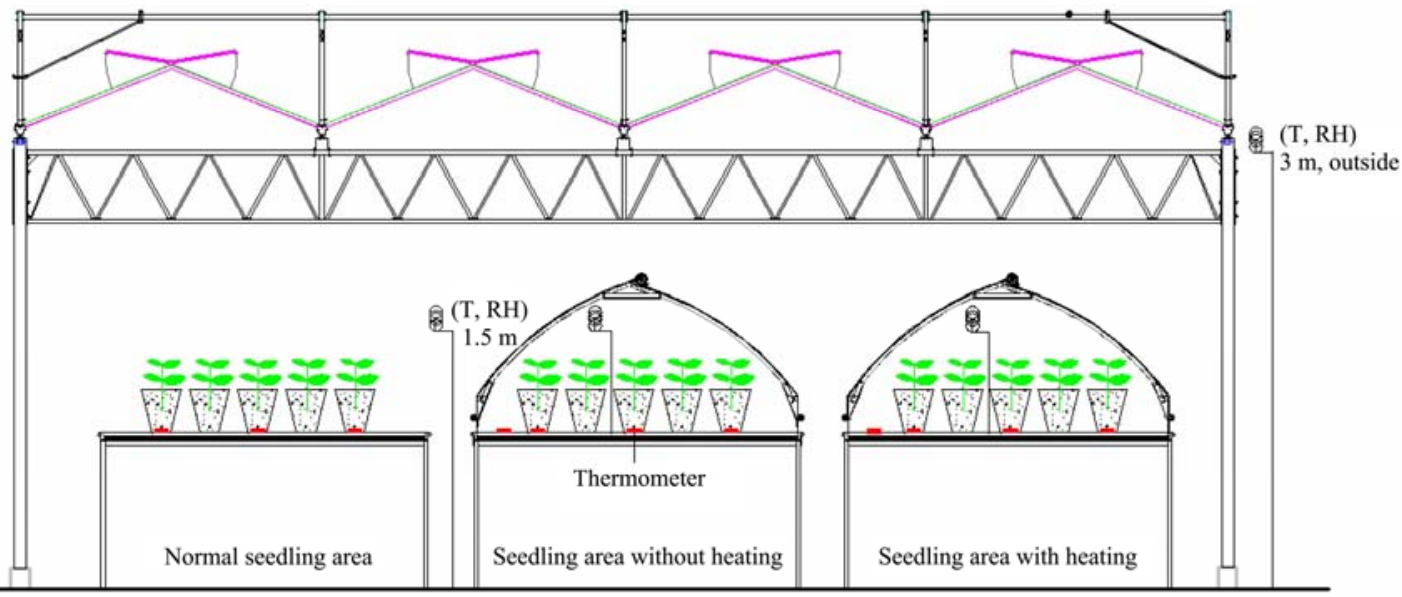

Figure 3 Experimental greenhouse structure and position of captors for measurement of different climatic parameters

\section{Results and discussion}

During the test period, the outside air temperature was between $-16.3^{\circ} \mathrm{C}$ and $6.6^{\circ} \mathrm{C}$, and the outside air relative humidity was between $16.6 \%$ and $99.8 \%$. The air temperature in the greenhouse was between $8.7^{\circ} \mathrm{C}$ and $28.7^{\circ} \mathrm{C}$ with auxiliary heating. The overall environmental change is shown in Figure 4.

\subsection{Effects on air temperature}

The main climatic factors that affect the growth and the precocity of the seedling production in the greenhouse include temperature and humidity, solar radiation. The optimum temperature range of tomato seedling is between $15^{\circ} \mathrm{C}$ and $21^{\circ} \mathrm{C}$. Temperatures above $26^{\circ} \mathrm{C}$ or below $10^{\circ} \mathrm{C}$, the crops suffer from heat and cold damage.

Figure 5 shows air temperature changes of outside greenhouse and seedling area at day time and night time. In the day time, the air temperature of the three seedling area has little difference. But at night, with the seedling root heating system on, the temperature has some difference. The average air temperature at night in the seedling area with heating was $1^{\circ} \mathrm{C}$ higher than that in the normal seedling area. It can be seen that the use of the root heating system had little effect on air temperature rise. The main reason was that heating material was laid under the seedling tray. Most of the heat was mainly transferred to the substrate by low temperature heat radiation, and a small part of the heat was convective with the air around. And for there were heat reflection film and insulation material, the heat can only be transferred vertically upward, and the heat transferred downward was little. The average temperature at night in the seedling area without heating was $1.8^{\circ} \mathrm{C}$ lower than that in the normal seedling area. The main reason was that the greenhouse was equipped with a hot water heating system. When the external thermal insulation covering film was dropped, the heat in the greenhouse was directly prevented from entering into the seedling area without active heating equipment, which resulted in the air temperature in the seedling area without heating was lower.

\subsection{Effects on substrate temperature}

The substrate temperature change curves are shown in Figure 6 The substrate change trend of three seedling areas was different. The substrate temperature in the seedling area without heating varied greatly from $2.25^{\circ} \mathrm{C}$ to $25.6^{\circ} \mathrm{C}$, while the substrate temperature in the seedling area with heating varied from $12.6^{\circ} \mathrm{C}$ to $25.5^{\circ} \mathrm{C}$. The average and minimum of substrate temperature in the seedling area with heating were $5.2^{\circ} \mathrm{C}$ and $7.4^{\circ} \mathrm{C}$ higher than in 
the seedling area without heating.

For the day change of substrate temperature, the seedling area with heating at night time is basically stable at about $20^{\circ} \mathrm{C}$. The changing trend of the normal seedling area was similar to seedling without heating, and the average temperature difference between these two areas was about $1{ }^{\circ} \mathrm{C}$. For seedling needs little substrate, and the heat capacity is little, which resulted in the substrate temperature change with the air temperature. But for the seedling area with heating, the thing has changed.

\subsection{Effects on seedbed surface temperature}

The seedbed surface temperature change curves are shown in Figure 7. The average and minimum of seedbed surface temperature in the seedling area with heating were $11.3^{\circ} \mathrm{C}$ and $14.3^{\circ} \mathrm{C}$ higher than in the seedling area without heating. The seedbed surface temperature in the seedling area without heating

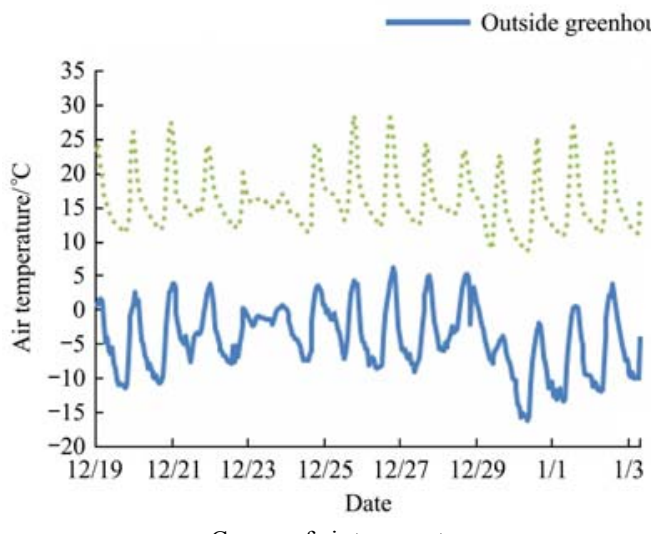

a. Curves of air temperature

changed greatly, ranging from $8.3^{\circ} \mathrm{C}$ to $29.9^{\circ} \mathrm{C}$, while that in the seedling area with heating ranged from $12.4^{\circ} \mathrm{C}$ to $29.1^{\circ} \mathrm{C}$. The seedbed surface temperature in the seedling area without heating was directly affected by air temperature, and there was no environmental control equipment installed for temperature regulation. The seedbed surface temperature in the seedling area with heating was directly controlled by the heating system. The seedbed surface temperature can be stably controlled at about $24^{\circ} \mathrm{C}$ in the heating period which was $16: 00$ to $9: 30$ in the next day. It can be seen that the temperature control performance of the system was stable and the temperature control error was small. In this period without heating, the seedbed surface temperature change trends of seedling areas were basically the same, which were directly controlled by the air temperature of the greenhouse.

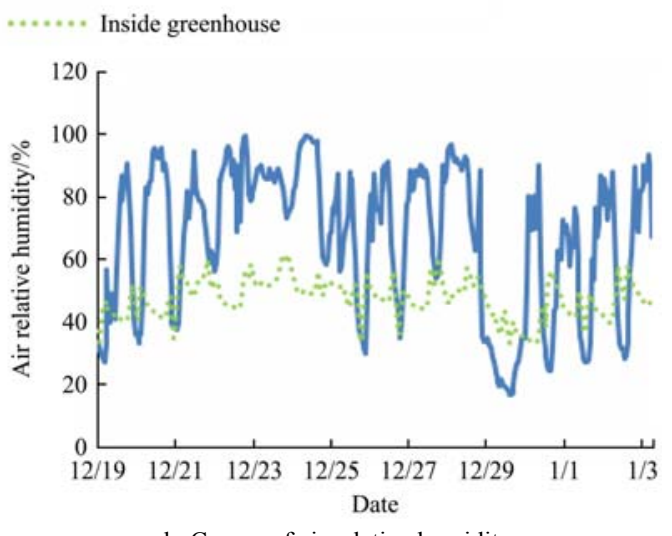

b. Curves of air relative humidity

Figure 4 Change of inside and outside environment
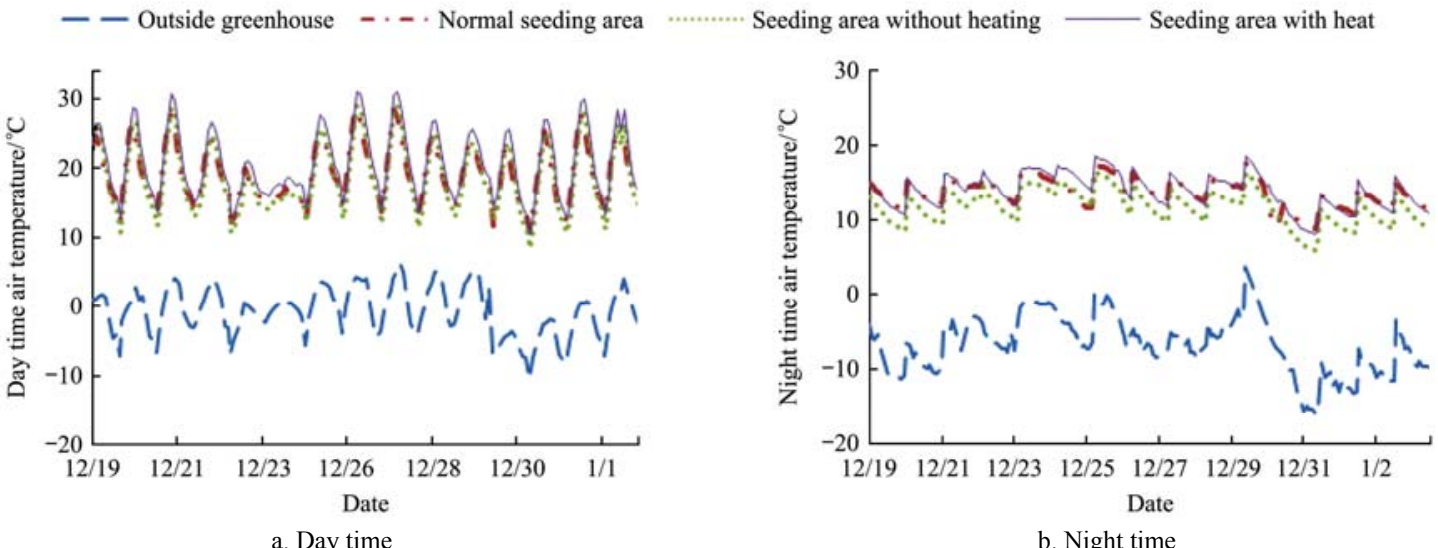

Figure 5 Change curves of air temperature

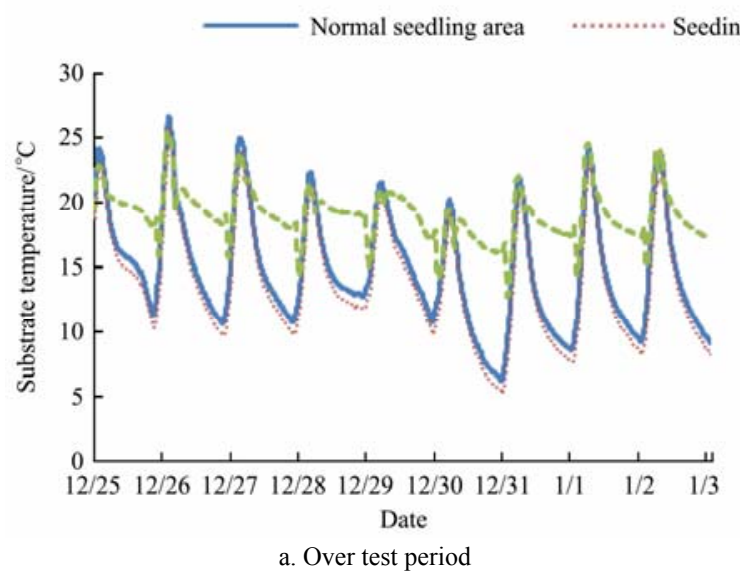

b. Night time

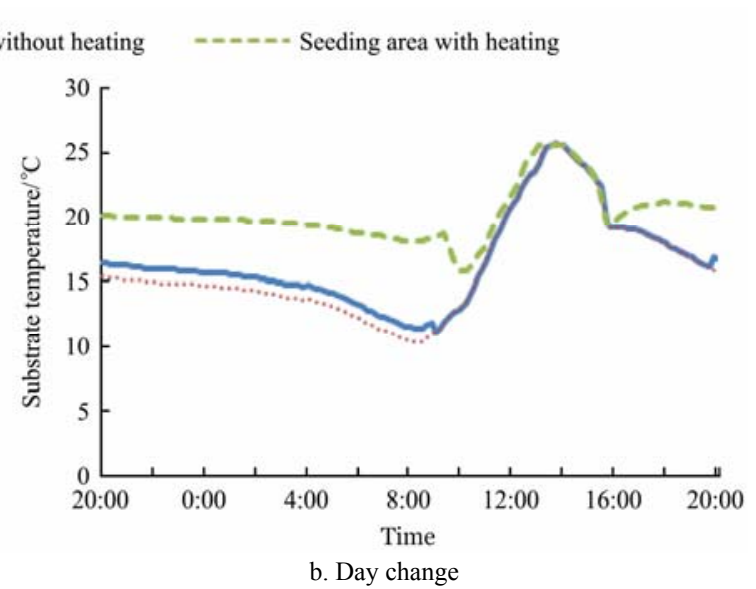

Figure 6 Substrate temperature change curves of overall test period and day change curves (December 26th) 

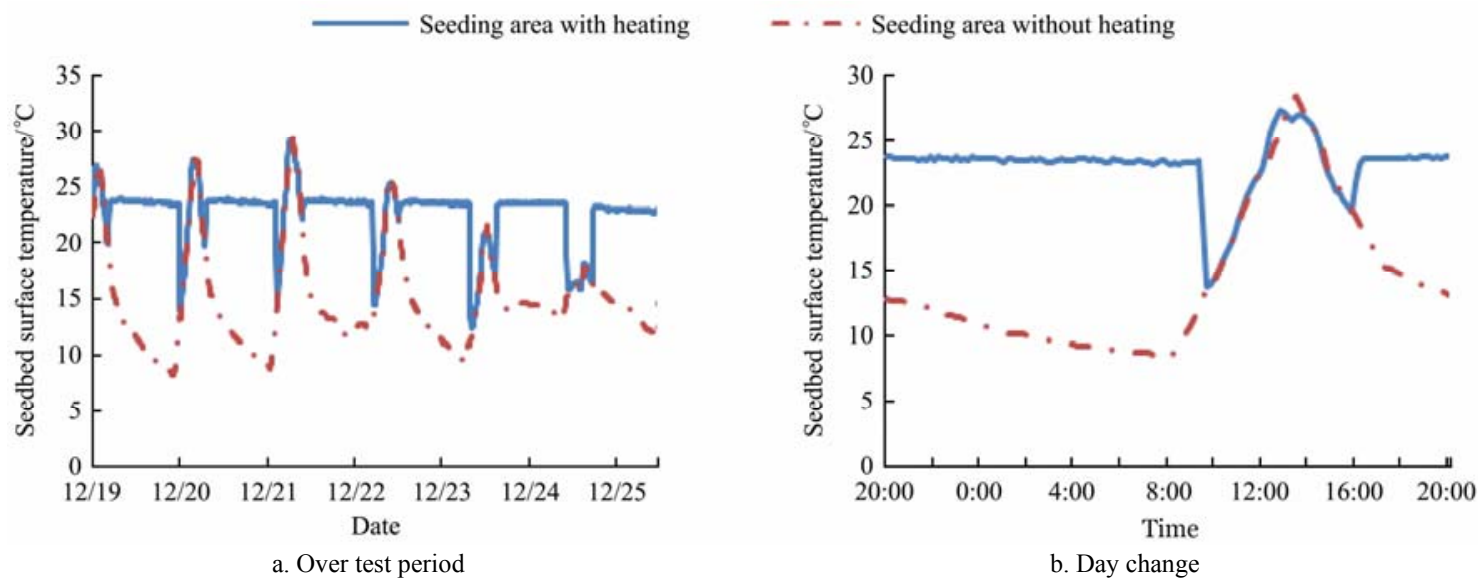

Figure 7 Seedbed surface temperature change curves of overall test period and day change curves (December 26th)

\subsection{Analysis of heating uniformity}

The minimum deviation degree of substrate temperature was used as the statistical index to evaluate the uniformity of the heating system. When the minimum deviation degree of a substrate temperature of each measuring point in the same depth layer was not more than $20 \%$ and the average value was not more than $10 \%$, the substrate temperature was considered to be uniform. The minimum deviation degree of substrate temperature can be calculated by Equation (5).

$$
\gamma=\frac{\bar{T}_{s}-T_{s \min }}{T_{s}} \times 100 \%
$$

where, $\bar{T}_{s}$ is the average temperature of each measuring point at the same measuring time, ${ }^{\circ} \mathrm{C} ; T_{s \min }$ is the minimum temperature of each measuring point at the same measuring time, ${ }^{\circ} \mathrm{C} ; T_{s}$ is the temperature of each measuring point at the same measuring time, ${ }^{\circ} \mathrm{C}$.

Nine substrate temperature measuring points of the same depth were arranged in the seeding area with heating, and the minimum deviation degree of all measuring points during the whole testing period was calculated, which is shown in Table 1. The results were that the minimum deviation degree of substrate temperature was between $2.83 \%$ and $10.95 \%$, and the average was $6.02 \%$, which were all less than the judging value.

Table 1 Substrate temperature minimum deviation degree

\begin{tabular}{ccc}
\hline \multirow{2}{*}{ Measuring points } & \multicolumn{2}{c}{ Minimum deviation degree } \\
\cline { 2 - 3 } & Change range & Average \\
\hline 1 & $2.83-9.32$ & 5.42 \\
2 & $2.91-9.41$ & 5.85 \\
3 & $2.97-8.88$ & 5.61 \\
4 & $3.05-9.64$ & 6.31 \\
5 & $3.14-10.95$ & 6.46 \\
6 & $3.04-9.55$ & 5.93 \\
7 & $3.01-10.65$ & 6.12 \\
8 & $3.07-10.73$ & 6.30 \\
9 & $3.14-10.43$ & 6.21 \\
\hline Average of minimum deviation degree & \multicolumn{2}{c}{6.02} \\
\hline
\end{tabular}

\section{Conclusions}

An experimental study was conducted to evaluate the effect of the seedling heat preservation and root zone heating system on the microclimate in the Venlo greenhouse. The presence of the heating system improves the seedling local microclimate during the nocturnal and winter periods with an average increase of the inside air temperature and substrate temperate by $1{ }^{\circ} \mathrm{C}$ and $5.2^{\circ} \mathrm{C}$. This improvement in the microclimate during the nocturnal periods had a very positive impact on seedling development and quality. The minimum deviation degree of substrate temperature was less than $20 \%$, and the average was less than $10 \%$. The greenhouse seedling heat preservation and root zone heating system can make the substrate temperature rise evenly, which can provide a good environment for the cultivation of high-quality seedlings.

Meanwhile, as a new type of heat dissipation end for civil heating, the cost of carbon crystal electric heating film was only RMB $¥ 20$ to RMB $¥ 40$ per square meter, which were $50 \%$ lower than the capillary tube, traditional boiler and heat dissipation end and hot air heating. The cost price of the capillary tube is RMB $¥ 50$ to RMB $¥ 70$ per square meter, which is $50 \%$ higher than that of hot air heating and circular wing radiator, which makes its initial investment in the early stage is relatively large. When there is no suitable low temperature heat source such as industrial waste heat, the follow-up operation cost will be high. If the initial investment cost of the greenhouse heating system is too high, it will be very difficult for greenhouse producers and operators to apply and popularize. However, the carbon crystal electric heating film heating system has low investment cost in the early stage and high electricity cost in the later stage, and it is more suitable for the production of greenhouse crops with high added value and high environmental requirements, such as seedling and potted flowers.

\section{Acknowledgements}

This work was financially supported by the National Key Research and Development Program of China (Grant No. 2017YFD0701500) and the Hebei Province Key Research and Development Program (Grant No. 19227214D).

\section{[References]}

[1] Hassen B, Mariem L, Amenallah G. A performance of a heat pump system connected a new conic helicoidal geothermal heat exchanger for a greenhouse heating in the north of Tunisia. Solar Energy, 2018; 171: 343-353.

[2] Reda H E H, Li M, Tang Y L. The evacuated tube solar collector assisted heat pump for heating greenhouses. Energy \& Buildings, 2018; 169: 305-318.

[3] Zhang B G, Fan X Y, Liu M, Hao W G. Experimental study of the burning-cave hot water soil heating system in solar greenhouse. Renewable Energy, 2016; 87: 1113-1120.

[4] Zhou N J, Yu Y X, Yi J P, Liu R.A study on thermal calculation method for a plastic greenhouse with solar energy storage and heating. Solar Energy, 2017; 142: 39-48. 
[5] Bazgaoua A, Fatnassib H, Bouhroudc R, Gourdoa L, Ezzaeria K, Tiskatinea R, et al. An experimental study on the effect of a rock-bed heating system on the microclimate and the crop development under Canarian greenhouse. Solar Energy, 2018; 176: 42-50.

[6] Abderrahim B, Hicham F, Rachid B, Kabira E, Lahoucine G, Ahmed W, et al. Efficiency assessment of a solar heating cooling system applied to the greenhouse microclimate. Materials Today: Proceedings, 2020; 24: $151-159$.

[7] Kavga A, Karanastasi E, Konstas I, Panidis T. Performance of an infrared heating system in a production greenhouse, IFAC Proceedings Volumes, 2013; 46(18): 235-240.

[8] Kawasaki Y, Matsuo S, Kanayama Y, Kanahama K. Effect of root-zone heating on root growth and activity, nutrient uptake, and fruit yield of tomato at low air temperatures. J. Jpn. Soc. Hortic. Sci., 2014; 83: 295-301.

[9] Gonzalez-Fuentes J A, Shackel K, Heinrich Lieth J, Albornoz F, Benavides-Mendoza A, Evans R Y. Diurnal root zone temperature variations affect strawberry water relations, growth, and fruit quality, Scientia Horticulturae, 2016; 203: 169-177.

[10] Attar I, Naili N, Khalifa N, Hazami M, Farhat A. Parametric and numerical study of a solar system for heating a greenhouse equipped with a buried exchanger. Energy Conversion and Management, 2013; 70: 163-173.

[11] Zhang H M, Jin H J, Ding X T, Yu J Z. Effects of different heating devices on cucumber seedling and plant growth in winter season. Chinese Cucurbits and Vegetables, 2012; 25(4): 12-15. (in Chinese)

[12] Zhao Y L, Yu X C, Li Y S, He C X, Yan Y. Application of electric carbon crystal soil-warming system for tomato production in greenhouse. Transactions of the CSAE, 2013; 29(4): 131-138. (in Chinese)

[13] Li Y S, Zhao Y L, He C X, Yan Y, Yu X C. Application of electric carbon crystal warming board for seedlings culture cucumber in greenhouse in winter. Journal of China Agricultural University, 2014; 19(6): 126-133. (in Chinese)
[14] Ding X M, He F, Duan J, Lian Q L, Zhang Q S. Design of low temperature heating system in solar greenhouse using capillary tube mat exchange. Transactions of the CSAE, 2013; 29(19): 178-184. (in Chinese)

[15] He F, Fu J L, Ding X M, Pan S J, Li Z X, Zhou C J. Design and test of seedbed hating system based on capillary network in solar greenhouse. Journal of China Agricultural University, 2017; 22(2): 123-128. (in Chinese)

[16] Beyza B, Halime P, Yildiz D. Root zone temperature control with thermal energy storage in phase change materials for soilless greenhouse applications. Energy Conversion and Management, 2013; 74: 446-453.

[17] Llorach-Massana P, Pena J, Rieradevall J, Montero J I. Analysis of the technical, environmental and economic potential of phase change materials (PCM) for root zone heating in Mediterranean greenhouses, Renewable Energy, 2017; 103: 570-581.

[18] Muhammad A, Wang X C, Muhammad Y, Muhammad U, Khurram Y, Yang $\mathrm{Z}$ J, et al. Performance evaluation of root zone heating system developed with sustainable materials for application in low temperatures. Sustainability, 2018; 10: 4130. doi: 10.3390/su10114130.

[19] Muhammad A, Zhang Z, Wang X C, Muhammad Y, Muhammad U, Rana $\mathrm{S} \mathrm{N}$, et al. An investigation of a root zone heating system and its effects on the morphology of Winter-Grown green peppers. Energies, 2019; 12: 933. doi: 10.3390/en12050933.

[20] Tan Y F, Guo L R, Chen J X, Zhang H Q. Test simulation and temperature control of carbon crystal electric heating system. Journal of Harbin Institute of Technology, 2012; 44(6): 70-73. (in Chinese)

[21] He J, Li Y X, Wang S. Design and application of carbon crystal electric heating system. Power Demand Side Management, 2016; 5: 25-28. (in Chinese)

[22] He F, Hou Y, Li K, Zhang Y F, Li Z X. Influence of root zone heating on seedling environment in solar greenhouse by carbon crystal electrothermal film. Northern Horticulture, 2018; 23: 60-64. (in Chinese) 